\title{
Teste de biocompatibilidade e resistência de membranas de látex em cães
}

\author{
Biocompatibility and resistance test of latex membranes in dogs
}

\author{
Marina Zimmermann ${ }^{\text {I* }}$ Alceu Gaspar Raiser ${ }^{\text {II }}$ Anna Laetícia da Trindade Barbosa ${ }^{\mathrm{I}}$ \\ Deisi Novosad ${ }^{\text {III }}$ Renata Pamela Barrachi Steffen ${ }^{\text {III }}$ Rafael Lukarsewsk ${ }^{\text {III }}$ \\ Marcelo Soares da Silva ${ }^{\mathrm{IV}}$ Renato Lindinger $^{\mathrm{IV}}$ Floriano Pastore Júnior $^{\mathrm{IV}}$
}

\section{RESUMO}

O látex natural extraído da seringueira (Hevea brasiliensis) possui propriedades indutoras de neovascularização e regeneração tecidual, comprovadas em várias espécies e em diferentes tecidos do organismo. Este estudo testou a biocompatibilidade e a resistência de três membranas de látex em seis cadelas, sendo duas dessas membranas ainda não utilizadas e uma já testada em estudos prévios. Os implantes foram colocados entre os músculos cutâneo e reto do abdome através de procedimento cirúrgico e, após 45 dias, foram removidos e submetidos a exames histológicos. Durante esse período, os animais foram avaliados quanto à dor e às alterações clínicas e macroscópicas nas membranas. Testes mecânicos de tração para determinação de deformação e resistência foram efetuados em amostras-controle. Pelos resultados obtidos, concluiu-se que as membranas testadas são compatíveis para substituir a bainha muscular em cães, exceto a membrana 2, por apresentar características de rejeição.

Palavras-chave: membrana de látex, biocompatibilidade, cães.

\section{ABSTRACT}

The natural latex extracted of the Rubber Tree, has properties to induce characteristics of tissue vascularization and regeneration that had been comproved in different species and tissues. This study tested the biocompatibility of three latex membranes in six dogs. Two of these membranes have not been used yet, while one of them has been tested in previous studies. Membranes were implanted between the cutaneous and the rectum of the abdomen muscles by a surgical procedure. In a forty five days period, the animals were evaluated for pain, clinical and macroscopic alterations of the membranes and, after the membranes were removed in order to submit them to histological exams. Mechanical traction tests were realized in control membranes to measure deformation and resistance. The results indicated that membranes are compatible, and able to substitute the muscular sheath in dogs, excepting membrane 2, because of it rejecting characteristics.

Key words: latex membranes, rabbits, biocompatibilities.

\section{INTRODUÇÃO}

O látex natural é um cicatrizante, uma defesa natural da planta. Muitas pesquisas que utilizaram este material como implante, em diferentes tecidos, têm demonstrado resultados satisfatórios, o que motiva a realização de novos trabalhos nesta área, em diferentes espécies. Próteses desse material foram desenvolvidas na Universidade de São Paulo em que a membrana de látex natural foi utilizada com sucesso na reconstrução do esôfago (MRUÉ, 1996) e na parede de cães. Os resultados revelaram que a membrana de látex como novo material de fonte biológica, possui características bioquímicas que o tornam capaz de interferir no processo de reparação tecidual, favorecendo a formação rápida e regular de novo tecido, além de ser de fácil manuseio, dispensando técnicas complexas para sua confecção e utilização (MRUÉ, 2000).

Em decorrência de bons resultados, houve um número crescente de pesquisas SADER (2000)

\footnotetext{
'Programa de Pós-graduação em Medicina Veterinária, Universidade Federal de Santa Maria (UFSM), 97105-900, Santa Maria, RS, Brasil. E-mail: veterinariamarina@yahoo.com.br. *Autor para correspondência.

IDDepartamento de Clínica de Pequenos Animais (DCPA), UFSM, Santa Maria, RS, Brasil.

IIICurso de Medicina Veterinária, UFSM, Santa Maria, RS, Brasil.

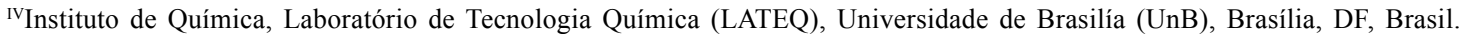


substituiu parcialmente o pericárdio de cães por membrana de látex com regeneração do pericárdio nativo. Trabalho recente utilizou a biomembrana de látex com polilisina a $0,1 \%$ na herniorrafia perineal em um cão, permitindo a oclusão do anel herniário, com formação de tecido de granulação e posterior retirada da membrana (PAULO et al., 2005a). No homem, a biomembrana de látex foi utilizada no tratamento de úlceras isquêmicas na perna, sendo considerada um importante agente indutor de tecido de cicatrização e remodelagem tecidual (FRADE, 2003). Em bovinos, ela foi empregada com eficácia em hernioplastias umbilicais recidivantes (RABELO et al., 2005). Pesquisa com reconstrução conjuntival de coelhos demonstrou favorecimento na cicatrização e neoangiogênese (PINHO et al., 2004). Em ratos, o uso da membrana de látex permitiu a formação de tecido conjuntivo fibroso de reparação, em defeitos iatrogênicos de parede abdominal (PAULO et al., 2005b). Além disso, o mesmo procedimento foi utilizado na reparação de falhas no crânio de ratos. Por fim, os pesquisadores acreditam que novas pesquisas apontam para a utilização da membrana de látex em osteoporose, odontologia e na reconstituição de ossos da face (ODONTOLOGIKA, 2003).

O objetivo deste estudo foi verificar, em cães, a biocompatibilidade e a resistência de duas membranas de látex em comparação a um modelo de membrana comercial já conhecido, a fim de facilitar a sua obtenção e baratear o custo. Com os resultados deste experimento, pretende-se selecionar uma ou mais membranas para utilização futura em outros tecidos.

\section{MATERIAL E MÉTODOS}

Foram utilizadas seis cadelas, sem raça definida, adultas, pesando de 8,0 a $12,0 \mathrm{~kg}$, provenientes do Biotério Central da Universidade Federal de Santa Maria. Os animais foram mantidos em recintos individuais, alimentados com ração comercial e água ad libittum. No pré-operatório, foram submetidas a jejum hídrico de $12 \mathrm{~h}$ e sólido de $24 \mathrm{~h}$, à tricotomia no abdome para o acesso cirúrgico e nos membros anteriores para acesso venoso. A anestesia foi feita com maleato de acepromazina $\left(0,1 \mathrm{mg} \mathrm{kg}^{-1}\right)$ e cloridrato de fentanila $\left(2,5 \mu \mathrm{g} \mathrm{kg}^{-1}\right)$ como medicação pré-anestésica via intramuscular e, após 15 minutos, as cadelas foram induzidas com propofol $\left(2 \mathrm{mg} \mathrm{kg}^{-1}\right)$ intravenoso, sendo mantidas em plano anestésico com halotano. A monitorização do ritmo e freqüência cardíaca foi feita em monitor eletrocardiógrafo e a saturação de oxigênio avaliada com oxímetro posicionado na língua do paciente. Em cada uma delas, foram aplicados $30 \mathrm{mg} \mathrm{kg}^{-1}$ de ampicilina sódica IV, 30min antes da cirurgia, como profilaxia antimicrobiana.
Nesses animais, foram implantados dois tipos de membranas de látex confeccionadas no Laboratório de tecnologia química da Universidade de Brasília (LATEQ - UnB) e uma membrana já em uso no comércio $^{a}$. As membranas foram agrupadas conforme sua composição: M1 - látex in natura (não centrifugado), o que reduz o custo da confecção; ácido fórmico, uma mistura vulcanizante, composta de mercaptobenzotiazol - MBT, um acelerador de vulcanização, que, associado ao poliisopreno da borracha, torna-se inerte; dietilditiocarbamato de zinco - ZDEC, um ultra-acelerador para borracha natural e sintética, muito utilizado em látex; óxido de zinco, um ativador para vulcanização e bactericida; e enxofre que funciona como agente de vulcanização (VULCANIZAR, 2005). As outras membranas correspondem a: M2 - látex in natura, mais enxofre (3ml) e ácido fórmico; M3 - látex centrifugado, polilisina $0,1 \%{ }^{a}$ (modelo comercial).

Para a implantação das membranas em cada animal, foi realizada a anti-sepsia tópica com álcooliodo-álcool, antes do procedimento cirúrgico. As membranas foram implantadas do lado direito e esquerdo, tendo como referência a linha média, sendo que a M1 e a M2 foram colocadas do lado direito e a M3 do lado esquerdo. Para a implantação, a bainha do músculo reto do abdome foi acessada por intervenção cirúrgica, e nela foram preparadas janelas para a fixação de amostras das membranas, de $2 \mathrm{~cm}^{2}$, com pontos simples isolados de fio mononáilon $\mathrm{n}$. 30 . A distância entre cada implante foi de $10 \mathrm{~cm}$. A reconstituição do acesso foi realizada com o fio poligalactina - 910, n.3-0, em sutura contínua, e da pele com mononáilon n. 3-0. Decorridos 45 dias da cirurgia, cada animal foi submetido a novo acesso cirúrgico para remoção das membranas, juntamente com o tecido adjacente.

No pós-operatório de cada intervenção, foi avaliada a dor aguda (Tabela 1) por sete dias, aplicado flunixin meglumine $\left(1,1 \mathrm{mg} \mathrm{kg}^{-1}\right)$ por três dias, e foram efetuados curativos diariamente até a retirada dos pontos ao sétimo dia. Durante 45 dias, em dias alternados, foram observadas as características físicas macroscópicas das feridas e classificadas de acordo com a reação local de cada membrana. Visando a facilitar a avaliação, foram estabelecidos escores para observar o grau de saliência de cada membrana implantada: grau zero - membrana não-palpável, sem saliência; grau 1 membrana palpável com suave saliência; grau 2 membrana palpável com forte saliência.

Após 45 dias, as membranas e tecidos adjacentes foram retirados e imediatamente acondicionados individualmente em frascos contendo formaldeído a $10 \%$, tamponados e encaminhados para 
Tabela 1 - Critérios para a avaliação da dor aguda no pós-operatório de cães.

\begin{tabular}{|c|c|c|c|}
\hline \multirow[b]{2}{*}{ Parâmetro avaliado } & \multicolumn{3}{|c|}{ Escore de intensidade } \\
\hline & 0 & 1 & 2 \\
\hline Batimentos cardíacos & Normal & Taquicardia & \\
\hline Movimentos respiratórios & Normal & Taquipéia & Padrão abdominal \\
\hline Temperatura & Normal 37,5 a $39,0^{\circ} \mathrm{C}$ & Hipertermia $>39,0^{\circ} \mathrm{C}$ & \\
\hline Salivação & Normal & Aumentada & \\
\hline Pupilas & Miose & Midríase & \\
\hline \multicolumn{4}{|l|}{ Luz ambiente } \\
\hline Estado mental & Dócil & Alerta/medo & Agressivo \\
\hline Vocalização & Ausência & Presença & \\
\hline Postura e atitude & Ereta e alegre & Arqueado ou deitado e triste & \\
\hline Resposta à manipulação & Não reage & Reação leve, esquiva-se & Reação brusca, morde \\
\hline Locomoção & Normal & Com dificuldade & Não movimenta \\
\hline Apetite & Normorexia & Hiporexia & Anorexia \\
\hline Ganho de peso & Igual ou ganho & Perda & \\
\hline Micção & Normal & $\begin{array}{l}\text { Com dificuldade, pouco e } \\
\text { freqüente }\end{array}$ & Não urina \\
\hline Defecação & Normal & Com dificuldade & Não defeca \\
\hline
\end{tabular}

De 0 a 4 - Animal não sente dor

De 5 a 6 - Animal com dor moderada.

De 7 acima - Animal com dor intensa.

processamento e estudo histológico. Cada amostra foi incluída em parafina e corada pela eosina-hematoxilina. Testes biomecânicos de tração direta foram realizados no laboratório de materiais de construção civil, em que se determinou o grau de deformação e resistência de cada membrana antes da implantação, exceto da M3, por limitações do equipamento. Para isso, preparam-se amostras de cada membrana medindo $15 \mathrm{~cm}$ de comprimento por $3 \mathrm{~cm}$ de largura; a espessura de cada amostra foi determinada com micrômetro, em que se obteve a média, após dez repetições para cada membrana.

O molde foi fixado por garra metálica com uma haste, e pesos de $100 \mathrm{~g}$ foram adicionados a ela, progressivamente, até sua estricção e posterior ruptura. Com uma régua, foi medido o grau de deformação da membrana a cada 30 segundos após a adição de cada peso. Este procedimento foi repetido três vezes para cada membrana. Calculou-se então o ângulo de deformação e a resistência do material.

\section{RESULTADOS E DISCUSSÃO}

No primeiro dia de pós-operatório, uma cadela apresentou sialorréia, duas estavam em alerta, três permaneceram deitadas. Não foi detectada manifestação de dor, o que se justifica pelo uso de anti-inflamatório no pós-operatório imediato.
Em uma cadela, drenou-se secreção purulenta na M2 no $20^{\circ}$ dia de pós-operatório, sendo realizada antibioticoterapia até a retirada da membrana. No procedimento de retirada das membranas, aos 45 dias, a M1 estava sem alterações macroscópicas em cinco cadelas, sendo que em uma delas observou-se secreção serosanguinolenta ao redor. A M2 estava sem alterações em quatro cadelas, e em uma estava dobrada, mas sem secreção. A cadela que apresentara secreção purulenta no pós-operatório apresentava a M2 com pus. A M3 estava sem alterações em cinco cadelas, e em uma foi observada sua migração em direção à M1, permanecendo contralateral a esta. De acordo com o escore pré-determinado, as membranas foram classificadas em: M1 grau 1 em todas as cadelas; M2 grau 1 e grau 2 em três cadelas, respectivamente e, M3 grau $0 \mathrm{em}$ todas as cadelas. Essa diferença de escore entre M1 e M3 deve-se ao fato da M3 possuir espessura de $100 \mu \mathrm{m}$, enquanto as outras possuem $1,4 \mathrm{~mm}$ em média. Já a M2 apresentou forte saliência, evidenciando reação local.

Optou-se por avaliar as membranas aos 45 dias para verificar se neste período havia presença de neovascularização, tecido neoformado e células indicativas de rejeição. As alterações histológicas evidenciadas aos 45 dias mostram, na área de interface tecido/membrana, diferentes graus de reação a cada membrana (Tabela 2). Os achados deste experimento, 
Tabela 2 - Características histológicas de membranas de látex submetidas ao teste de biocompatibilidade em cães.

\begin{tabular}{ll}
\hline M 1 & $\begin{array}{l}\text { Tecido conjuntivo frouxo rico em vasos sanguíneos, tecido conjuntivo denso predominante. Infiltrado } \\
\text { inflamatório mononuclear focal e multifocal discreto. Reação leve. }\end{array}$ \\
M 2 & $\begin{array}{l}\text { Tecido conjuntivo frouxo rico em vasos sanguíneos, tecido conjuntivo denso predominante. Infiltrado } \\
\text { inflamatório mononuclear discreto. Presença de plasmócitos. } \\
\text { Tecido conjuntivo frouxo rico em vasos sanguíneos, tecido conjuntivo denso predominante. Infiltrado } \\
\text { inflamatório mononuclear discreto a moderado. }\end{array}$ \\
\hline
\end{tabular}

M1 - M3 = Membranas de látex agrupadas conforme sua composição.

neovascularização, presença de infiltrado inflamatório predominantemente monocítico e formação de tecido conjuntivo denso em sua maioria, é similar aos resultados encontrados por MRUÉ (1996). Essa autora, em estudo com biomembrana de látex centrifugado em esôfago de cães, relatou presença de infiltrado inflamatório predominantemente monocítico, na segunda semana de avaliação, evoluindo para redução deste e organização das fibras colágenas do tecido cicatricial na quarta semana de avaliação. MENTE et al. (2001) efetuaram teste de biocompatibilidade com membrana de látex em ratos, no período de 21 dias, e também comprovaram a ausência de rejeição. Esses dados discordam de PAULO et al. (2005b), que obtiveram na análise histológica de ratos com implante de biomembrana de látex aos 5 e 120 dias presença de infiltrado inflamatório multinucleado, linfócitos, plasmócitos, eosinófilos e raros mastócitos, sendo o implante rejeitado, embora, permitindo a formação de tecido de reparação. Pelo que se observa, a membrana de látex atua como um implante temporário que induz reação tecidual de grau variável, sendo este novo tecido o responsável pela reparação definitiva no local de implantação.

O látex centrifugado perde grande quantidade de proteínas, incluindo as causadoras de reações alérgicas e aquelas que promovem a neovascularização e, portanto, exige maiores cuidados no preparo, além de ser mais dispendioso (SILVA, 2006 - informe verbal). Já o látex não-centrifugado possui um custo inferior e permanece com todas as suas proteínas, inclusive as indutoras de neovascularização, em maior quantidade.

Produtos derivados do látex são usados largamente na prática médica em forma de sondas, drenos e indumentárias da equipe, entre outros. As reações alérgicas são raras, e devem-se principalmente ao teor de proteínas contido no produto e à adição de talco, que, ao reagir com certas proteínas, promove uma potencialização do efeito alergênico (MRUÉ, 1996). Os três modelos de membranas apresentados neste experimento apresentaram baixa alergenicidade, sendo que a M3 é constituída basicamente por carbono e hidrogênio, compatíveis com o organismo animal. Quanto aos outros componentes das formulações das membranas M1 e M2, esses estão em quantidades mínimas e estáveis nas membranas; entretanto, não são conhecidos estudos que comprovem sua neutralidade. A diferença entre M1 e M2 está na presença do enxofre, que em M2 está em maior quantidade. A M2 apresentou pior resultado por ter baixo índice de vulcanização, devido à ausência de aceleradores e ativadores, que estão presentes na M1. Na vulcanização, a matriz polimérica da borracha é ligada internamente por fortes ligações dissulfídicas, diminuindo assim o contato efetivo dos constituintes da borracha com o meio. Como conseqüência, o contato destes, inclusive das proteínas alergênicas, são maiores nesta membrana (SILVA, 2006 - informe verbal), causando a rejeição observada.

Os testes de tração aos quais as amostras foram submetidas revelaram que a composição influencia na deformação e resistência. As membranas M1 e M2 são diferentes entre si, sendo a M1 muito superior à M2 com relação à resistência e deformação, dados esses que são diretamente proporcionais (Tabela 3). A M3, por possuir $100 \mu \mathrm{m}$ não resistiu nem ao peso mínimo de $340 \mathrm{~g}$ do aparelho. É importante salientar que a espessura da amostra influencia diretamente sua resistência, sendo essa diretamente proporcional, quando se comparam amostras do mesmo material. Dependendo da utilização de cada membrana, pode-se inferir que todas possuem resistência suficiente para sustentação como substituto de bainha muscular.

Segundo PAULO et al. (2005a), provavelmente existam diferenças entre espécies, tecidos receptores e entre a fabricação da membrana de látex, indicando a necessidade da continuidade de pesquisas neste campo. Em outra pesquisa conduzida com as membranas de látex implantadas no abdome de ratos, PAULO et al. (2005b) verificaram que elas foram eliminadas a partir do 5o dia de pós-operatório, sofrendo completa extrusão em média aos 13,8 dias. Em cães, MRUÉ (2000) observou a eliminação das próteses 
Tabela 3 - Valores médios de espessura, médias e desvios-padrão de diferentes amostras para deformação e resistência de membranas de látex submetidas ao teste mecânico de tração.

\begin{tabular}{lccc}
\hline Membrana & $\begin{array}{c}\text { Espessura } \\
(\mathrm{mm})\end{array}$ & $\begin{array}{c}\text { Deformação } \\
(\mathrm{cm})\end{array}$ & $\begin{array}{c}\text { Resistência } \\
(\mathrm{kg})\end{array}$ \\
\hline M1 & 1,56 & 119,0 & 18,75 \\
M2 & 1,44 & 13,40 & 1,19 \\
M3 & 0,1 & $\begin{array}{c}\text { Não } \\
\text { mensurado }\end{array}$ & $<0,43$ \\
\hline
\end{tabular}

M1 - M3 = Membranas de látex agrupadas conforme sua composição.

esofágicas aos dez dias de pós-operatório, enquanto RABELO et al. (2005) não observaram rejeição em hernioplastias umbilicais de bovinos. Nos cães deste experimento, foi observada rejeição da M2 testada até o 45 dia de pós-operatório, com presença de secreção purulenta em um animal, além de plasmócitos no exame histológico. O seu uso, portanto, está contra-indicado. Já a M1 e a M3 não apresentaram características de rejeição neste experimento e podem ser utilizadas como indutoras de tecido fibroso na área de implantação.

\section{CONCLUSÃO}

As diferentes formulações para as membranas de látex testadas oferecem resistência apropriada para a sua implantação na reparação da bainha muscular em cães; no entanto, apenas as formulações das membranas 1 e 3 são biocompatíveis.

\section{AGRADECIMENTOS}

Ao Laboratório de Tecnologia Química - LATEQ - Universidade de Brasília.

Ao Laboratório de Materiais de Construção Civil LMCC - UFSM

Ao Laboratório de Cirurgia Experimental - LACE - UFSM.

À Professora Dra.Dominguita Luhers Graça.

Ao Conselho Nacional de Desenvolvimento Científico e Tecnológico $(\mathrm{CNPq})$, pela concessão de bolsa à pesquisadora Marina Zimmermann.

\section{FONTES DE AQUISIÇÃO} Grosso - MS.

${ }^{\text {a }}$ Biocure - Pele Nova Biotecnologia S/A, Mato

\section{COMITÊ DE ÉTICA E BIOSSEGURANÇA}

Projeto submetido e aprovado no Comitê de Ética da Universidade Federal de Santa Maria, processo n. 23081.008621/2006-88.

\section{INFORMEVERBAL}

Marcelo Soares da Silva. Endereço: QI 14, conjunto "D", casa 15, Guará 1, Brasília- DF. E-mail: sr.marcelo.silva@gmail.com. 30/08/2006. Contato online.

\section{REFERÊNCIAS}

FRADE, C.A.M. Úlcera de perna: caracterização clínica e perfil imunohistopatologico da cicatrização na presença da biomembrana de látex natural da seringueira. 2003. 164f. Tese (Doutorado em Medicina) - Universidade de São Paulo. Faculdade de Medicina de Ribeirão Preto.

MENTE, E.D. et al. Transplante de ilhotas pancreáticas em dispositivo de imunoisolamento celular - resultados iniciais. Acta Cirúrgica Brasileira, v.16, supl.1, 2001. Acesso em 10 fev. 2006. Online. Disponível em: http//www.scielo.br/ scielo.php? script=sci_arttext\&pid=S0102$86502001000500024 \&$ Ing $=$ en $\& n m=$ is $0 \&$ t $\operatorname{lng}=\mathrm{pt}$

MRUÉ, F. Neoformação tecidual induzida por biomembrana de látex natural com polilisina. Aplicabilidade em neoformação esofágica e da parede abdominal. Estudo experimental em cães. 2000. 112f. Tese (Doutorado em Medicina) - Universidade de São Paulo. Faculdade de Medicina de Ribeirão Preto.

MRUÉ, F. Substituição do esôfago cervical por prótese biosintética de látex. Estudo experimental em cães. 1996. 86f. Dissertação (Mestrado em Medicina) - Universidade de São Paulo. Faculdade de Medicina de Ribeirão Preto.

ODONTOLOGIKA. Descoberto novo uso para o látex: reconstrução óssea, Conexão. São Paulo, $21 \mathrm{fev}$. 2003. Capturado em 26 abr. 2006. Online. Disponível na Internet: http://www.conexaomaster.com.br/ index.php?pag $=$ noticia\&lang $=$ pt\&id $=2517$

PAULO, N.M. et al. Biomembrana de látex natural (Hevea brasiliensis) com polilisina a $0,1 \%$ para herniorrafia perineal em um cão. Acta Scientiae, v.33, n.1, p.79-82, 2005a.

PAULO, N.M. et al. Membrana de látex da seringueira (Hevea brasiliensis), com e sem polilisina a $0,1 \%$ e tela de marlex na reconstrução de defeitos iatrogênicos da parede abdominal de ratos. Acta Scientiae, v.20, n.4, p.305, 2005 b.

PINHO, E.C.C.M. et al. Uso experimental da biomembrana de látex na reconstrução conjuntival. Arquivo Brasileiro de Oftalmologia, v.67, p.27-32, 2004.

RABELO, E.R. et al. Emprego do compósito látex, polimida e polilisina a $01 \%$ na correção cirúrgica de hérnias umbilicais recidivantes em bovinos leiteiros. Acta Scientiae, v.33, n.2, p.169-175, 2005 .

SADER, S.L. et al. Substituição parcial do pericárdio de cães por membrana de látex natural. Revista Brasileira Cirurgia Cardiovascular, v.15, p.338-344, 2000.

VULCANIZAR. Matéria Prima, Vulcanizar.com.br. 2005. Capturado em 02 mai. 2006. Online. Disponível na Internet: http://www.vulcanizar.com.br/home_p.asp. 